\title{
A Rare Presentation of Acquired Port Wine Stain in an Elderly Male
}

\author{
Satyendra Kumar Singh ${ }^{1}$, Prasanna Kumar Jha ${ }^{1}$ \\ ${ }^{1}$ Department of Dermatology and Venereology, Institute of Medical Sciences, Banaras Hindu University, India
}

\section{ABSTRACT}

Acquired port wine stain though an uncommon entity that develops later in life, resembles congenital port wine stain morphologically and histologically. Congenital port wine stains are vascular lesions caused by progressive ectasia of blood vessels which is located in the vascular plexus of the dermis. Congenital port-wine stains may be associated with Sturge Weber syndrome causing neurological and eye abnormalities such as glaucoma. Here we report a 60 -year-old male presenting with a complaint of asymptomatic reddish patches over the nose for 15 years.

Keywords: Nodular; Portwine; Stain

\section{Correspondence:}

Dr Prasanna Kumar Jha, Junior Resident III Department of Dermatology and Venereology, Institute of Medical Sciences, Banaras Hindu University, India

ORCID ID: 0000-0001-8475-6611

Email: jha_prasanna@hotmail.com

Submitted: $5^{\text {th }}$ May 2021

Accepted: $25^{\text {th }}$ June 2021

Source of Support: None

Conflict of Interest: No

Citation: Singh SK, Jha PK. A Rare Presentation of Acquired Port Wine Stain in an Elderly Male. NMJ 2021;4(1):457-8. DOI 10.3126/nmj.v4i1.36714

\section{INTRODUCTION}

Port-wine stains (PWS) are congenital as well as acquired vascular lesions caused by progressive ectasia of blood vessels located in the vascular plexus of the dermis. ${ }^{1}$ Acquired Port wine stains are an uncommon entity developing later in life, but morphological and histologically similar to the congenital lesions. We hereby report a case of a 60-year-old male who acquired PWS for about 15 years.

\section{\# CASE REPORT}

A 60-year-old male presented in Banaras Hindu University, Varanasi Dermatology outpatient department with a chief complaint of asymptomatic reddish patches over the nose for 15 years. There was no history of drug intake, trauma, eczema, or topical application. He had no other constitutional symptoms. There was no family history of a similar illness.

On examination, non-blanching reddish plaques with nodularity were present over the nose causing disfigurement of the face (fig $1)$.

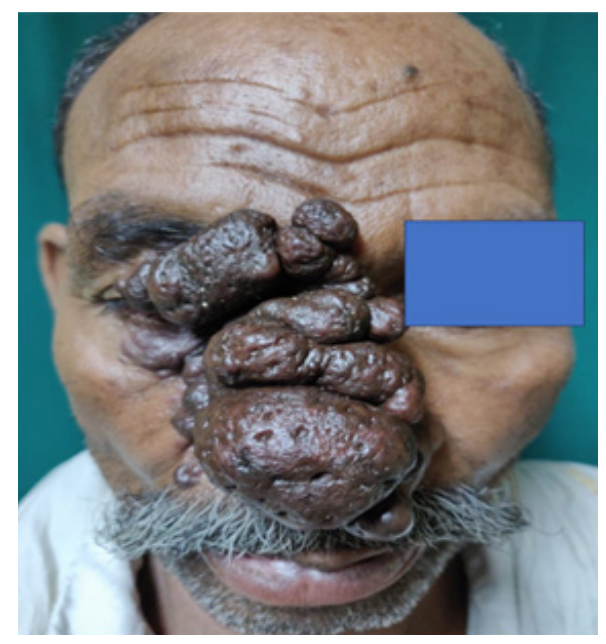

Figure 1: non-blanching reddish plaques with nodularity, firm on palpation of size $7 \times 2 \times 3 \mathrm{~cm}$. (Permission was obtained for publication of the image) 
The patient was sent for a magnetic resonance imaging scan of the brain and it was found to be within normal limits. Base upon the clinical findings and investigations a provisional diagnosis of acquired port-wine stain was made. An incisional biopsy was performed which was sent for histopathology. Histopathological examination revealed a substantial increase in the number of dilated slightly thick-walled capillaries within the papillary and upper reticular dermis. A few capillaries in the superficial and deep plexus were also dilated. A sparse superficial perivascular lymphohistiocytic infiltrate was present. The overlying epidermis was unaffected. The histopathology was suggestive of Port wine stain (fig. 2).

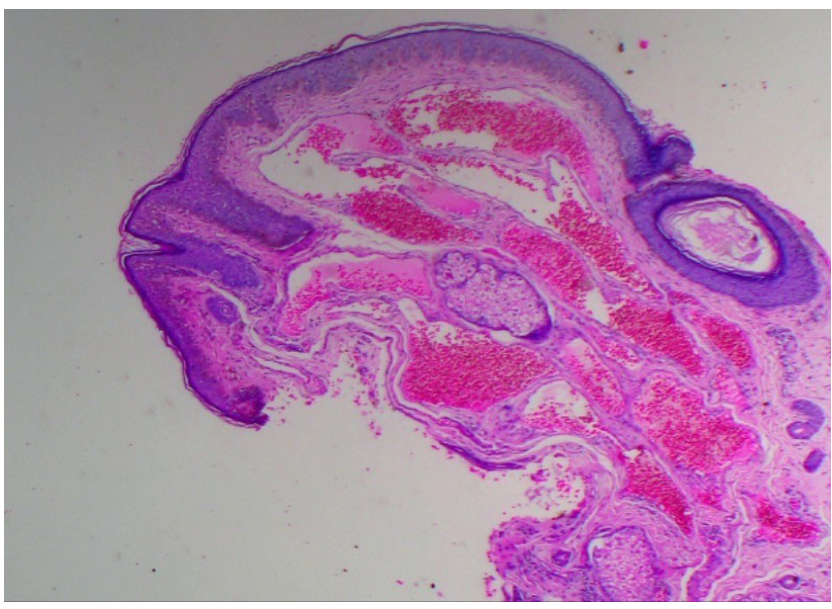

Figure 2: Microphotograph showing a substantial increase in the number of dilated slightly thick-walled capillaries within the papillary and upper reticular dermis. A few capillaries in the superficial and deep plexus were also dilated. A sparse superficial perivascular lymphohistiocytic infiltrate was present. The overlying epidermis was unaffected ( HE stain X 100).
Based on history, clinical findings, investigation, and histopathology final diagnosis of acquired port-wine stain was made. Laser treatment was discussed with the patient, but then he was lost to follow up.

\section{DISCUSSION}

There are various reports suggestive of acquired port-wine stain caused by antecedent trauma. ${ }^{1}$ In our case, there was no history of precedent trauma. Various treatment options for congenital port wine stain have been discussed in the literature but few focuses have been given on its acquired variant. Laser is based on selective photo thermolysis of the selected vessels. ${ }^{2}$ Laser treatment has been the mainstay of treatment for port-wine stain. For congenital lesions, pulsed dye laser has been used as a standard treatment, though relapse is common. ${ }^{3}$ Treatment, if started at an early phase of lesion provides better outcome. ${ }^{4}$ There is a chance of development of nodularity or associated pyogenic granuloma if treatment is delayed. ${ }^{5}$ Various first-generation lasers like Argon laser have been used in the past with variable results and adverse effects like scarring. ${ }^{6}$ Alexandrite laser of wavelength $755 \mathrm{~nm}$ has been used primarily for dark or resistant capillary malformations. ${ }^{7} \mathrm{Nd}$ : YAG laser of wavelength 1064 has been found beneficial for resistant capillary malformations, but there is an increased chance of scarring and ulceration. ${ }^{8}$ Other therapies like intense pulsed light and photodynamic therapy have been tried but less effective compared to laser treatment. ${ }^{9,10}$

This case was reported because of its rarity in presentation and thus identification and differentiation need to be done between congenital and acquired entities, the former of which can be associated with neural and ophthalmic defects.

\section{REFERENCES}

1. Adams BB, Lucky AW. Acquired Port-wine Stains and Antecedent Trauma: Case Report and Review of the Literature. Arch Dermatol. 2000;136(7):897-9. $\underline{\text { Crossref }}$

2. Anderson RR, Parrish JA. Selective photothermolysis: precise microsurgery by selective absorption of pulsed radiation. Science. 1983;220(4596):524-7.Crossref

3. Savas JA, Ledon JA, Franca K, Chacon A, Nouri K. Pulsed dye laser-resistant port-wine stains: mechanisms of resistance and implications for treatment. Br J Dermatol. 2013;168(5):941-53. Crossref

4. Geronemus RG, Ashinoff R. The medical necessity of evaluation and treatment of port-wine stains. J Dermatol Surg Oncol. 1991;17(1):76-9. $\underline{\text { Crossref }}$

5. Brightman LA, Geronemus RG, Reddy KK. Laser treatment of portwine stains. Clin Cosmet Investig Dermatol. 2015;8:27-33. Crossref
6. Geronemus RG. Argon laser for the treatment of cutaneous lesions. Clin Dermatol. 1995;13(1):55-8. Crossref

7. Izikson L, Anderson RR. Treatment endpoints for resistant port wine stains with a $755 \mathrm{~nm}$ laser. J Cosmet Laser Ther. 2009;11(1):52-5. Crossref

8. McGill DJ, MacLaren W, Mackay IR. A direct comparison of pulsed dye, alexandrite, KTP and Nd:YAG lasers and IPL in patients with previously treated capillary malformations. Lasers Surg Med. 2008;40(6):390-8. Crossref

9. Piccolo D, Di Marcantonio D, Crisman G, et al. Unconventional use of intense pulsed light. Biomed Res Int. 2014;2014:618206. Crossref

10. Chen JK, Ghasri P, Aguilar G, et al. An overview of clinical and experimental treatment modalities for port wine stains. J Am Acad Dermatol. 2012;67(2):289-304. Crossref 